\title{
EFFECTS OF MICROBIOLOGICAL CONTAMINATION IN THE QUALITY OF BIODIESEL FUELS
}

\author{
G.S. DODOS * \\ T. KONSTANTAKOS \\ S. LONGINOS \\ F. ZANNIKOS
}

Received: 09/12/11

Accepted: 09/03/12

\author{
Laboratory of Fuel Technology and Lubricants \\ School of Chemical Engineering \\ National Technical University of Athens, Greece \\ Heroon Polytechniou 9, 15780 Zografou, Athens, Greece
}

*to whom all correspondence should be addressed: e-mail: gdodos@central.ntua.gr

\begin{abstract}
The introduction to the European Market of biodiesel blends along with the minimization of the sulphur content in automotive diesel has rejuvenated the research interest on the microbial stability of diesel fuel. Several microorganisms are able to metabolize hydrocarbons contained in conventional fuels and particularly in diesel and jet stocks. With the advent of FAME (Fatty Acid Methyl Esters) as a diesel fuel substitute there has been an increase in the number of samples suspect of microbial contamination with confirmative results. The aim of this study was to investigate the microbiological stability of FAME/diesel blends and consequently the impact of microbial proliferation on their quality. A commercially available FAME was blended with Ultra-Low Sulphur (ULSD) and Low Sulphur (LSD) conventional automotive diesel fuels in mixing ratios of 5, 10 and 20 $\% \mathrm{v} / \mathrm{v}$. The resulting blends were contaminated with bottom-water of known viable microbial colonies and were stored for a period of 16 weeks. During storage the microbiological growth was evaluated by employing both semi-quantitative and quantitative methodologies. At the same time the devolution of certain quality parameters, namely oxidation stability and acid number, which could be influenced by microbial growth was examined. The overall results reveal the need to establish a scheduled inspection plan adapted to the diesel fuel supply chain infrastructure aiming to control and remedy efficiently the microbiological growth issues.
\end{abstract}

KEYWORDS: Microbial activity, Fatty Acid Methyl Esters, diesel fuel supply chain, oxidation stability, acid value.

\section{INTRODUCTION}

Micro-organisms' growth in the petroleum hydrocarbons has first been reported in the last decade of the 19th century (Miyoshi, 1895). However the contamination problems and implications have started to cause concerns in the 1950s (Graef, 2003; Hill, 2003). At that time the U.S.A. Air Force confronted extended microbial contamination of the JP-4 jet fuel. The climax was a B-52 crash that was directly attributed to clogging of fuel system screens and filters due to microbial growth.

Several microorganisms are able to metabolize hydrocarbons contained in conventional fuels. The necessary nutrients are provided mainly from the fuel hydrocarbons and secondly from the additives contained in it. It has been demonstrated that the middle distillates - aviation and diesel fuel - are more prone to microbial growth (Gaylarde et al., 1999; Dzięgielewski et al., 2009) since the hydrocarbon chains in the range of $\mathrm{C} 10-\mathrm{C} 18$ are readily utilized as carbon source from microorganisms. Although distillation processes "sterilize" the fuel, however water, dust and microorganisms can easily enter through the tankage and fuel transport system. Water is essential for microbial growth and proliferation. Consequently, microbes concentrate at sites within fuel systems where water accumulates (Gaylarde et al., 1999; Passman, 2003). Microbial activity and proliferation takes place mainly between the fuel-water interface where the availability of nutrients and water is optimum. As a result a formation of an intermediate sticky, membranous-like phase called biofilm - is observed. Microorganisms can also colonize the bottom, the walls and headspace 
surfaces of tanks and pipelines. The kinds of microorganisms that proliferate within fuel systems include bacteria, yeasts and filamentous fungi. Moreover obligate anaerobes, such as sulphate reducing bacteria (SRB), has been reported to grow, largely into the anoxic zones of the bottom sludge and sediments. The fuel phase generally only contains aerobic microbes. (Gaylarde et al., 1999; Passman, 2003).

Uncontrollable microbial activity may gradually degrade the fuel quality (Bento and Gaylarde, 2001). Microbial contamination can cause fuel turbidity, formation of bottom sludge and sediments, accompanied sometimes by an unpleasant odor. Contamination will be propagated to several sites of the fuel supply chain via distribution and transport systems. The effects of the metabolic byproducts are considerably more noticeable. The most commonly recognized symptom of microbial contamination is filter plugging. Other symptoms attributed to microbial activity have to do with pinhole leaks in tanks and pipelines due to Microbiologically Induced Corrosion (MIC), an electrochemical bio-corrosion process enhanced by the metabolites (e.g. hydrogenase) of the SRBs. (Videla and Herrera, 2005). Finally extended use of contaminated fuel has been associated with malfunction and shortened life of several engine parts.

The introduction to the European Market of biodiesel blends along with the minimization of the sulphur content in automotive diesel $(\max 10 \mathrm{ppm})$ has rejuvenated the research interest on the microbial stability of diesel fuel. Biodiesel is a renewable alternative fuel for diesel engines with nontoxic and biodegradable characteristics consisting of Fatty Acid Methyl Esters (FAME) mainly of vegetable oils and animal fat origin. Its chemical composition along with its hydroscopic nature makes it more "biologically active" and as a result the final blends could be more prone to microbiological contamination. (Dodos et al., 2009; Schleicher et al., 2009; Sorensen et al., 2011). On the other hand it is suggested that the decrease of sulfur content in automotive diesel may also play an important role to the promotion of microbial growth. During hydrodesulfurization process sulfur - as well as aromatic/phenolic - compounds are severely reduced or removed from the fuel. Since these compounds are considered to be good growth inhibitors, their elimination may enhance microbial activity. (Chapman, 2011; Gaylarde,1999). However limited published experimental data exist concerning the impact of sulfur minimization on diesel fuel's microbial growth.

Higher levels of biodiesel-diesel blends have recently been established according to the latest European specifications regarding automotive diesel fuel (EN 590:2009). The maximum FAME concentration nowadays accounts for $7 \% \mathrm{v} / \mathrm{v}$ and the mixing ratio is expected to increase more in the forthcoming years within the context of further reducing the greenhouse gases emissions. Along with the addition of FAME as fuel substitute at higher mixing ratios, there has been an increase in the number of samples suspect of microbial contamination, with confirmative results. The Greek diesel fuel supply chain was one of the first to experience an escalation in contamination symptoms (Dodos et al., 2009). The country's climate approximating the optimal microbial growth physiological range could be one reason for this. Suppliers and downstream users have been reporting problems such as filter clogging and excess sedimentation and sludge formation in storage tanks - with them being directly connected to microbiological activity. Nevertheless, this unforeseen escalation of such instances has also revealed the lack or sparse knowledge for this kind of issues particularly within the last stages of the diesel fuel supply chain.

Based on this background the aim of this study was to investigate the effect of the microbiological contamination in certain quality parameters of biodiesel fuel such as oxidation stability and acid value. The oxidation process affects the fuel quality since the species formed during oxidative procedures causes the fuel to deteriorate. On the other hand, acid value demonstrates the content of FFA (Free Fatty Acids) and is a good parameter for monitoring biodiesel fuel quality during storage. Increased acidity is the result of the formation of shorter chain fatty acids and acidic secondary oxidation products. Moreover the impact of sulfur content on the microbial activity was evaluated. For this reason a commercially available FAME was blended with two types of conventional automotive diesel having different sulphur content. The resulting blends were inoculated with contaminated water and stored. During storage the microbial growth rate was monitored and the evolution of oxidation stability and acid value was examined. 


\section{EXPERIMENTAL}

\subsection{Biodiesel Sample}

A commercially available FAME without antioxidant additive was obtained from a Greek biodiesel manufacturer and was used in mixing ratios with conventional diesel fuel. The quality parameters and the fatty acid composition of the examined fame are listed in Table 1 and Table 2 respectively. Regarding fuel properties, FAME satisfy the basic applicable requirements outlined in the European Standard EN14214. The fatty acid analysis showed that the FAME under examination is composed primarily of linoleic $(53.7 \mathrm{wt} \%)$ and oleic $(28.3 \mathrm{wt} \%)$ acid. The other main fatty acids are palmitic (8.9 $\mathrm{wt} \%)$ and stearic (3.8 wt \%). Very low levels of linolenic acid have been detected (0.1 wt \%).

Table 1. Properties of biodiesel (FAME)

\begin{tabular}{l|cccc}
\hline Property & Units & FAME & EN14214 limits & Method \\
\hline Ester content & $\% \mathrm{~m} / \mathrm{m}$ & 98.6 & $\min 96.5$ & EN 14103 \\
Density at $15^{\circ} \mathrm{C}$ & $\mathrm{kg} \mathrm{m}^{-3}$ & 885 & $860-900$ & EN 12185 \\
K.Viscosity at $40^{\circ} \mathrm{C}$ & $\mathrm{mm}^{2} \mathrm{~s}^{-1}$ & 4.25 & $3.50-5.00$ & EN 3104 \\
Total sulphur & $\mathrm{mg} \mathrm{kg}^{-1}$ & 2 & $\max 10.0$ & EN 20846 \\
Water content & $\mathrm{mg} \mathrm{kg}^{-1}$ & 377 & $\max 500$ & EN 12937 \\
CFPP & ${ }^{\circ} \mathrm{C}$ & -2 & $\max +5$ & EN 116 \\
Acid value & $\mathrm{mg} \mathrm{KOH} \mathrm{g}^{-1}$ & 0.3 & $\max 0.50$ & EN 14104 \\
\hline
\end{tabular}

Table 2. Fatty acid composition of FAME

\begin{tabular}{lrcc}
\hline \multicolumn{2}{c}{ Fatty Acids } & \multicolumn{1}{c}{ Chemical structure } & Weight (\%) \\
\hline Myristic & $\mathrm{C} 14: 0$ & $\mathrm{CH}_{3}\left(\mathrm{CH}_{2}\right)_{12} \mathrm{COOH}$ & $0.2 \%$ \\
Palmitic & $\mathrm{C} 16: 0$ & $\mathrm{CH}_{3}\left(\mathrm{CH}_{2}\right)_{14} \mathrm{COOH}$ & $8.9 \%$ \\
Stearic & $\mathrm{C} 18: 0$ & $\mathrm{CH}_{3}\left(\mathrm{CH}_{2}\right)_{16} \mathrm{COOH}$ & $3.8 \%$ \\
Oleic & $\mathrm{C} 18: 1$ & $\mathrm{CH}_{3}\left(\mathrm{CH}_{2}\right)_{7} \mathrm{CH}=\mathrm{CH}\left(\mathrm{CH}_{2}\right)_{7} \mathrm{COOH}$ & $28.3 \%$ \\
Linoleic & $\mathrm{C} 18: 2$ & $\mathrm{CH}_{3}\left(\mathrm{CH}_{2}\right)_{3}\left(\mathrm{CH}_{2} \mathrm{CH}=\mathrm{CH}\right)_{2}\left(\mathrm{CH}_{2}\right)_{7} \mathrm{COOH}$ & $53.7 \%$ \\
Linolenic & $\mathrm{C} 18: 3$ & $\mathrm{CH}_{3}\left(\mathrm{CH}_{2} \mathrm{CH}=\mathrm{CH}\right)_{3}\left(\mathrm{CH}_{2}\right)_{7} \mathrm{COOH}$ & $0.1 \%$ \\
Arachidic & $\mathrm{C} 20: 0$ & $\mathrm{CH}_{3}\left(\mathrm{CH}_{2}\right)_{18} \mathrm{COOH}$ & $1.1 \%$ \\
Behenic & $\mathrm{C} 22: 0$ & $\mathrm{CH}_{3}\left(\mathrm{CH}_{2}\right)_{20} \mathrm{COOH}$ & $0.6 \%$ \\
\hline
\end{tabular}

\subsection{Diesel Samples}

Two different types of automotive diesel fuel, an ultra-low sulphur diesel fuel (ULSD) and a low sulphur diesel fuel (LSD), were obtained by a Greek refinery and were used in all the experiments as base fuels in the FAME/diesel blends. The diesel fuel samples comprised of distillates from hydrodesulphurization units, and there were free of additives. The main difference between the two fuels consists in their sulphur content. LSD is an outdated fuel not complying with the latest sulphur specifications (EN590, 2009). However, it was utilized in order to investigate whether the minimization of sulphur has any impact on the fuel's microbial stability. The fuel properties are presented in Table 3, along with the standard methods that were used for their determination.

\subsection{Preparation of biodiesel blends}

The FAME sample was blended separately with ULSD and LSD in mixing ratios of $5 \% \mathrm{v} / \mathrm{v}$ (B5), 10 $\% \mathrm{v} / \mathrm{v}$ (B10) and $20 \% \mathrm{v} / \mathrm{v}$ (B20). All the samples were examined regarding physicochemical properties such as oxidation stability and acid value.

\subsection{Inoculation of fuel samples}

The prepared diesel/biodiesel fuel samples were inserted each into a $1 \mathrm{~L}$ glass container and were inoculated with bottom water of a contaminated commercial automotive diesel fuel at a 4:1 fuel-water ratio. Prior to inoculation process the above mentioned bottom water was filtered and the microbial content was determined by a dip -slide method. The density of the colonies in the inoculation water was found to be about $10^{6}$ colony forming units per $\mathrm{ml}$. 
Table 3. Properties of the base fuels ULSD and LSD

\begin{tabular}{l|ccccc}
\hline Property & Units & ULSD & LSD & EN 590 limits & Test Methods \\
\hline K.Viscosity at $40^{\circ} \mathrm{C}$ & $\mathrm{mm}^{2} \mathrm{~s}^{-1}$ & 2.68 & 2,68 & $2.00-4.50$ & EN ISO 3104 \\
Density at $15{ }^{\circ} \mathrm{C}$ & $\mathrm{kg} \mathrm{m}^{-3}$ & 828 & 830 & $820-845$ & EN ISO 3675 \\
Sulphur content & $\mathrm{mg} \mathrm{kg}^{-1}$ & 6 & 31 & $10 \mathrm{max}$ & EN ISO 20846 \\
Water content & $\mathrm{mg} \mathrm{kg}^{-1}$ & 24 & 25 & $200 \mathrm{max}$ & EN ISO 12937 \\
CFPP & ${ }^{\circ} \mathrm{C}$ & -9 & 0 & $-5 \mathrm{~min}$ & EN 116 \\
Cetane Index & & 52.3 & 56.1 & $46 \mathrm{~min}$ & EN ISO 4264 \\
$\begin{array}{l}\text { Polycyclic aromatic } \\
\text { hydrocarbons }\end{array}$ & $\% \mathrm{~m} / \mathrm{m}$ & 4.3 & 3 & $11 \mathrm{max}$ & EN 12916 \\
\hline
\end{tabular}

\subsection{Storage/Incubation of the fuel samples}

After inoculation the fuel blends were stored at ambient conditions for a period up to 16 weeks. Physical aeration was employed via a small headspace aperture. The samples were subjected to gentle shaking periodically while the rest of the time they were left tranquil. At certain intervals small samples were collected from the fuel phase close to the fuel/water interface and examined regarding the microbial growth and quality parameters such as oxidation stability and acid value. For comparison reasons, non contaminated (blank) fuel blends were also stored for an equal period and under the same conditions and were examined similarly to the above series of determinations, as well. All the experiments were performed in duplicate.

\subsection{Microbial growth monitoring}

The microbial contamination of the samples under examinations was evaluated by employing two different methods.

\subsubsection{Colony Forming Unit Tests (Dip Slide Method)}

This is a semi-quantitative test comprising of a sterile container with a slide covered with a suitable agar medium enriched with a nutrient. Dip Slide method can detect total aerobic bacteria along with yeasts and fungi. The slides were immersed into the fuel sample and were placed in an incubator at a temperature of $28^{\circ} \mathrm{C}$ for a period ranging from $24 \mathrm{~h}$ to 3 days. After incubation the density of the microorganisms' colonies growing on each medium were compared with the model density charts and the results were reported as CFU $\mathrm{ml}^{-1}$ (colony forming units per $\mathrm{ml}$ ).

\subsubsection{Assessment of Adenosine Tri-Phospahte (ATP Bioluminescence)}

A HyLite $®$ Fuel Test apparatus was employed in order to assess the viable microbial biomass by ATP Bioluminescence, in accordance with ASTM D7463 standard method. The system quantifies the ATP present in the sample and it is able to detect the metabolic activity of bacteria, yeast and moulds, including anaerobe microorganisms. The fuel sample under examination was mixed with an enzyme reagent (luciferase) which reacted with any ATP present to produce light. The amount of light emitted was measured using a luminometer and the results were reported as Relative Light Units per liter [RLU $\left.\mathrm{It}^{-1}\right]$ of sample. Greater readings of emitted light were indicative of the heavier contamination of the fuel sample. The repeatability of the method was calculated using the following equation: $r=0.9243^{*}(X-16)$ (ASTM D 7463).

\subsection{Oxidation stability measurements}

The oxidation stability measurements were carried out in a Rancimat apparatus, according to the accelerated oxidation method EN15751 regarding diesel/FAME blends. Samples of $7.5 \mathrm{~g}$ were analyzed under constant airflow of $10 \mathrm{~L} \mathrm{~h}^{-1}$ and at $110^{\circ} \mathrm{C}$ heating block temperature. The oxidation stability was measured as Induction Period (IP- in hours). According to the standard method the calculation of precision estimates was conducted by employing the equation $r=0.22027+0.04344^{\star} X$ (EN15751).

\subsection{Acid value determinations}

For the determination of acid value (AV) by titration, the European Standard EN14104 for Oil and Fat derivatives was followed. The repeatability limit of this method is equivalent to $0.02 \mathrm{mg} \mathrm{KOH} \mathrm{g}^{-1}$. 


\section{RESULTS AND DISCUSSION}

\subsection{Microbial growth}

Microbiological growth testing has been conducted after 4, 8 and 16 weeks of incubation. The results from the microbial contamination monitoring with the CFU tests after 8 and 16 weeks of incubation are presented in Table 4. Negligible or zero density of colonies was determined on the dip-slides after 4 weeks of incubation and these results are not included in the table. Noticeable bacterial content was obtained during the $8^{\text {th }}$ week concerning the ULSD biodiesel blends. No significant differentiations was observed in the number of bacteria and the colonies' density was reported as being just below the lower detection limit of the dip slide method, i.e. $<10^{3} \mathrm{cfu} \mathrm{ml}^{-1}$. At the same time the microbial activity in the LSD biodiesel blends was suppressed since neither bacterial nor yeasts/moulds growth appeared on the corresponding slides. After 16 weeks elapsed time, the microbial growth in the ULSD blends has escalated ranging from $10^{4}-10^{6} \mathrm{cfu} \mathrm{ml}^{-1}$ In the B20 ULSD sample the detected contamination was heavier compared to the B5 and B10 counterparts. Similar observations have been reported in the literature (Dodos, 2009; Schleicher et al., 2009; Sorensen et al., 2011) and it could be reckoned that these results are indicative of the negative effect that the higher concentration of FAMEs has on the microbial stability of the diesel/biodiesel blends. On the other hand it is worth noticing that according to the results obtained from the CFU tests the microbial growth in the LSD biodiesel blends was still inhibited after 16 weeks of incubation, with the exception of the B5 sample which demonstrated a small amount of contamination. This implies that higher sulfur content of the fuel might be antagonistic to microbial growth.

Table 4. Microbial growth in the examined fuel blends with the CFU tests

\begin{tabular}{l|cccc}
\hline \multirow{2}{*}{$\begin{array}{l}\text { Fuel } \\
\text { Blend }\end{array}$} & \multicolumn{4}{|c}{ Microbial Growth $\left(\mathrm{CFU} \mathrm{ml}^{-1}\right)$} \\
& 8 weeks & 16 weeks \\
& USD & LSD & ULSD & LSD \\
\hline B5 & $<10^{3}$ & 0 & $10^{4}$ & $<10^{3}$ \\
B10 & $<10^{3}$ & 0 & $10^{4}$ & 0 \\
B20 & $<10^{3}$ & 0 & $10^{5}-10^{6}$ & 0 \\
\hline
\end{tabular}

ATP Bioluminescence tests were conducted after 16 weeks of incubation. Figure 1 illustrates the average results obtained from the Hy-Lite apparatus. Despite the poor repeatability of the standard method the actual deviation of the measured values in the duplicate was found to be much lower. Again the unfavorable effect of the FAME concentration is obvious. The general trend of the results depict that the level of contamination increases with higher mixing ratios of FAME in the fuel blend. Both B20 biodiesel blends demonstrated the strongest microbial activity from all the samples under examination. The dissimilarity between the high microbial contamination of the B20 LSD blend detected in ATP Bioluminescence test and the zero result obtained from the CFU test could be attributed to the ability of the former kit to detect the metabolic activity from a widest range of microorganisms.

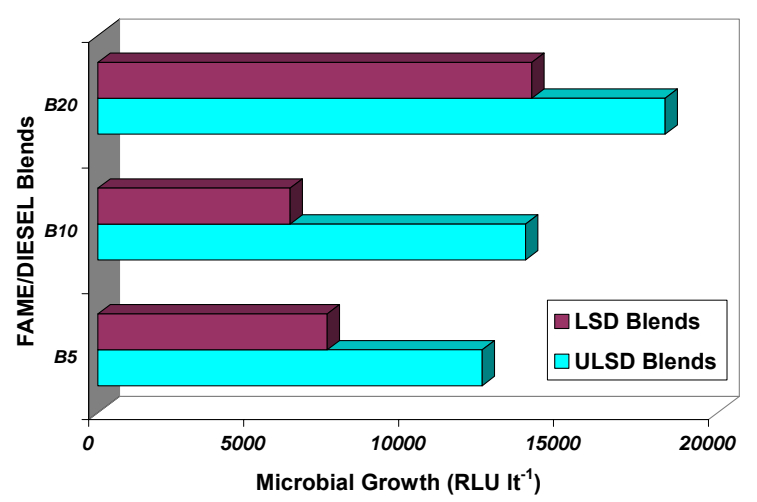

Figure 1. ATP Bioluminescence detection of microbial contamination level in the examined fuel blends after a period of 16 weeks 
Nevertheless, the LSD blends gave considerably lower values of $\mathrm{RLU}^{\mathrm{t}} \mathrm{t}^{-1}$ indicative of the lower levels of microbial growth present in the fuels with higher sulfur content. These findings reinforce the previously mentioned observation concerning the impact of sulfur reduction on the fuel's microbial instability.

Table 5. Initial oxidation stability of the FAME/diesel blends

\begin{tabular}{|c|c|c|}
\hline FAME/diesel & Initial Oxi & ability (h) \\
\hline blend & ULSD Blends & LSD Blends \\
\hline B5 & 39.93 & 19.69 \\
\hline B10 & 25.37 & 16.59 \\
\hline B20 & 14.57 & 10.29 \\
\hline
\end{tabular}

\subsection{Oxidation Stability}

At first the initial oxidation stability of the prepared fuel blends was evaluated. These results are presented in Table 5. B5/ULSD, B10/ULSD and B5/LSD samples fulfill the EN590 interim requirement that designates a minimum value of $20 \mathrm{~h}$ oxidation stability concerning biodiesel blends containing up to $7 \%$ v/v FAME (EN 590, 2009).
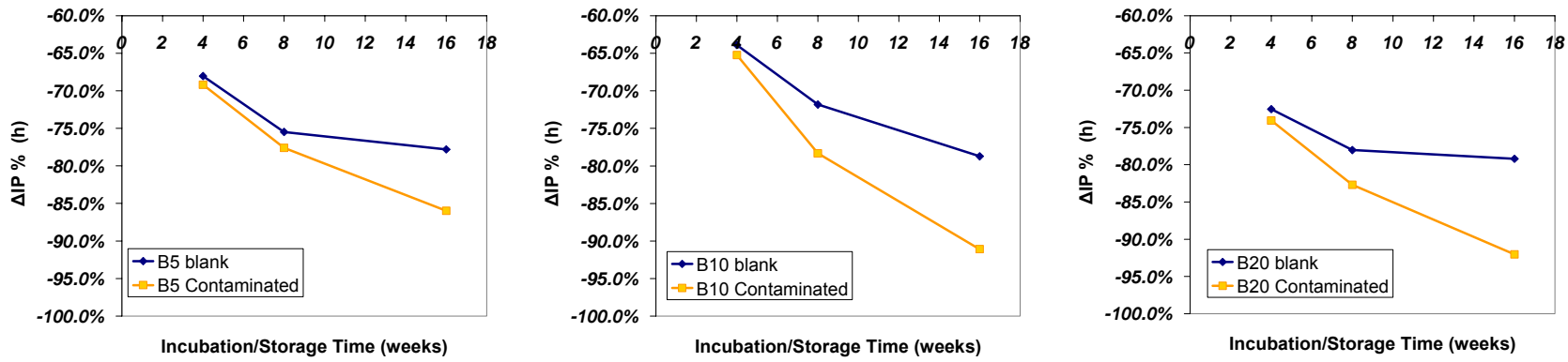

Figure 2. Percent decrease of the oxidation stability for contaminated and blank ULSD blended B5, B10 and B20 fuel samples during storage time
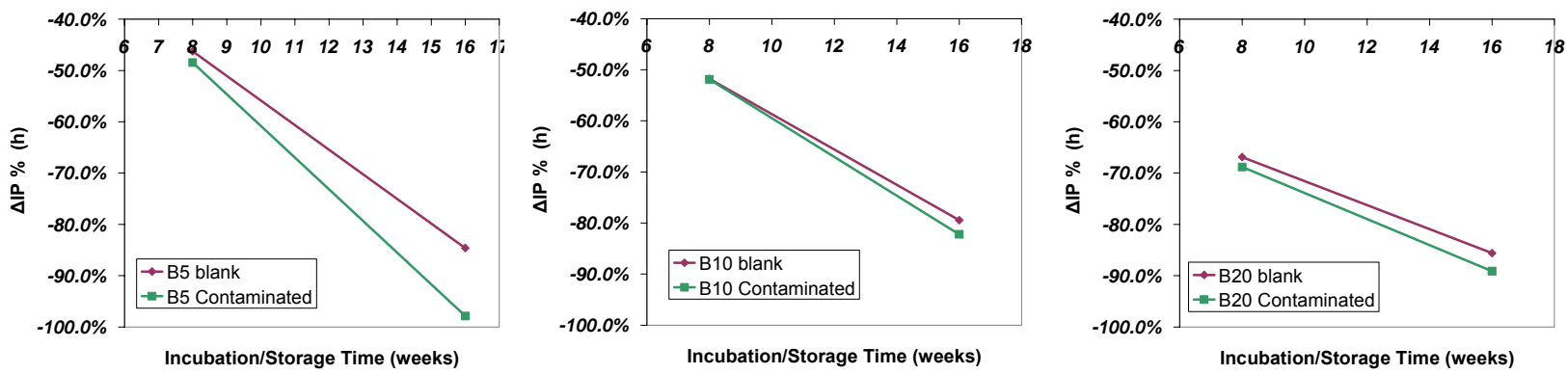

Figure 3. Percent decrease of the oxidation stability for contaminated and blank LSD blended B5, B10 and B20 fuel samples during storage time

Figures 2 and 3 demonstrate the alterations in the oxidation stability of the blank and the contaminated ULSD and LSD samples respectively, in terms of their percentage decrease during the storage period. With the exception of B5/LSD sample the oxidation stability devolution of the contaminated LSD samples depicted more or less the same gradient with the blank ones even after 16 weeks of incubation. In absolute values the corresponding IP determinations in all but one case fall within the repeatability of the method. Regarding the ULSD blends the differentiations in the oxidation stability between the blank and the contaminated samples are more obvious. The variations broaden throughout the incubation period since the deterioration rate of the inoculated samples appears to be quicker. Compared to the blank ULSD blends significant reduction in the oxidation stability particularly of the more heavily contaminated B10 and B20 samples was observed after 16 weeks of incubation. 


\subsection{Acid Value}

In figure 4 the evolution of the acid value is presented graphically for ULSD and LSD blends. Measurement in the samples under examination were conducted at the beginning (before inoculation) and after 16 weeks of incubation. The initial acid value of pure FAME is given in Table 1 and it is fairly below the upper limiting value designated by EN 14214. Consequently the prepared blends at the beginning possess acceptable almost equal acidity. After 16 weeks incubation acid values have increased in both the blank and the contaminated blends. However the inoculated blends produced considerably higher values with the B20/LSD blend having the more profound increment. Despite the heavier contamination detected in the ULSD blends, the evolution of AV is lower. This lower acidity production rate of the ULSD blends can be explained by the higher oxidation stability they exhibited (Bondioli, 2002).
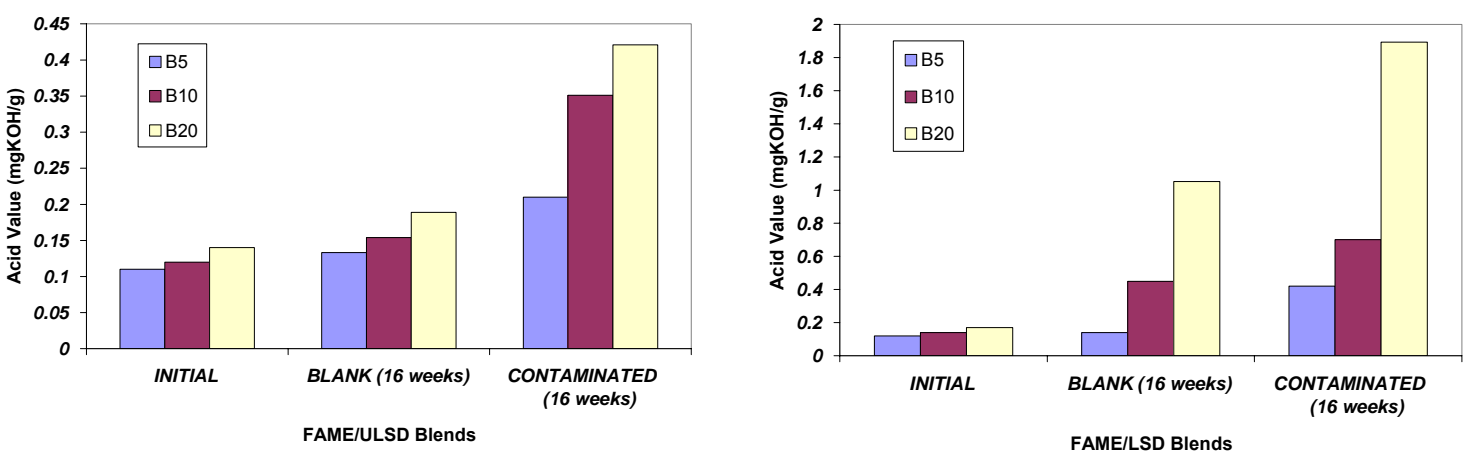

Figure 4. Evolution of the acid value for contaminated and blank ULSD and LSD blended B5, B10 and B20 fuel samples after 16 weeks storage time

\section{CONCLUSIONS}

A commercially available FAME was blended with Ultra-Low Sulphur and Low Sulphur conventional automotive diesel and the resulting B5, B10 and B20 blends were inoculated with contaminated water and stored for 16 weeks. During storage the microbial growth rate, the oxidation stability and the acid value were monitored in order to examine the effect of the microbiological contamination on these quality parameters. The results could be interpreted as follows.

- As a general trend, increased FAME concentration up to $20 \% \mathrm{v} / \mathrm{v}$ contributed to reduced microbial stability of the final fuel blend.

- Microbial growth can affect the oxidation stability and the acidity of biodiesel fuels. When high levels of microbial contamination had been detected in a sample the deterioration rate was appearing faster. On the other hand the contaminated blends produced considerably higher acid values after 16 weeks contrary to the blank ones

- The minimization of the sulfur content seems to allow enhanced microbial activity

Generally, the overall results along with the reported incident and problems reveal the need to establish a scheduled inspection plan adapted to the diesel fuel supply chain infrastructure aiming at controlling and remedying efficiently the microbiological growth issues.

\section{REFERENCES}

Bento F.M. and Gaylarde C.C. (2001) Biodeterioration of stored diesel oil: studies in Brazil, International Biodeterioration \& Biodegradation, 47, 107-112.

Bondioli P. (2002) Evaluation of biodiesel storage stability using reference methods, Eur. J. Lipid Sci.Technol., 104, 777-784.

Chapman R.L. (2011) ULSD Corrosion. Finally, an answer?, Petroleum Equipment Institute (PEI) Journal $2^{\text {nd }}$ Quarter, 61-63.

Dodos G.S., Perdiou V. and Zannikos F. (2009) Effect of Biodiesel in the Microbiological Growth through the Diesel Fuel Supply Chain, Proceedings from the $7^{\text {th }}$ Pan-Hellenic Scientific Conference on Chemical Engineering 2009.

Dzięgielewski W. and Sarnecki J. (2009) Discussion on microbial contamination of naval fuels, Polish Maritime Research, 3(61), 41-44. 
EN 590:2009, Automotive fuels-Diesel-Requirements and test methods, European Committee for Standardization (CEN)

Gaylarde C.C., Bento F.M. and Kelley J. (1999) Microbial contamination of stored hydrocarbon fuels and its control, Revista de Micribiologia, 30, 1-10.

Graef H.W. (2003) An analysis of microbial contamination in military aviation fuel systems, Thesis, Air Force Institute Of Technology, USA.

Hill T. (2003) Microbial growth in aviation fuel, Aircraft Engineering and Aerospace Technology, 75(5), 497-502.

Miyoshi M. (1895) Die Durch bohung von membranen durch Philzfaden, Jahrb. Wiss Botan., 28, 269-89.

Passman F.J. editor (2003) Fuel and fuel system microbiology, fundamentals, diagnosis, and contamination control, ASTM International.

Schleicher T., Werkmeister R., Russ W. and Meyer-Pittroff R., (2009) Microbiological stability of biodiesel-diesel-mixtures, Bioresource Technology, 100, 724-730

Sorensen G., Pedersen D.V., Norgaard A.K., Sorensen K.B. and Nygaard S.D. (2011) Microbial growth studies in biodiesel blends, Bioresource Technology, 102, 5259-5264.

Videla H.A. and Herrera L.K. (2005) Microbiologically influenced corrosion; looking to the future, International Microbiology 8, 69-180. 